\title{
The fatty acid composition of milk available at retail over the course of one year
}

K E Kliem, D I Givens

University of Reading, Reading, United Kingdom

Email:k.e.kliem@reading.ac.uk

Introduction Milk and dairy products are the greatest single source of saturated fatty acids (SFA) in the human diet, contributing to between 30 and $40 \%$ of total SFA intake in the UK (Henderson et al., 2003; Hulshof et al., 1999). Intake of SFA in the UK exceeds current guidelines thus increasing cardiovascular disease risk. Research has focused on strategies to reduce SFA in milk fat by altering dairy cow diet (Givens and Kliem, 2008). However such studies have only been conducted on an experimental scale and it is not known if these changes would still be apparent in retail milk composited from numerous farms. There are also no contemporary data on SFA in retail milk and how this changes throughout the year. Since UK consumption of semi-skimmed milk is still rising (Givens and Kliem 2008) the objective of the current study was to assess concentration of SFA and other fatty acids in retail milk over the course of one year.

Materials and methods Semi-skimmed milk $(550 \mathrm{ml})$ was purchased from five supermarkets within a 5 mile radius of the laboratory at the same time every month over the course of one year (one month was omitted). Milk was aliquotted and stored at $-20^{\circ} \mathrm{C}$ until analysis. Lipid in $1 \mathrm{ml}$ milk was extracted in duplicate using ethanol, diethylether and hexane, and transesterified to fatty acid methyl esters (FAME) using methanolic sodium methoxide (Kliem et al., 2008). FAME were separated using a gas chromatograph temperature programme (Kliem et al., 2008). Milk fatty acids were expressed as $\mathrm{g} / 100 \mathrm{~g}$ fatty acids. Data were analysed as groups of fatty acids using analysis of variance for effects of month and supermarket.

Results The SFA content of retail milk peaked in January (mean \pm SEM $67.6 \pm 0.35 \mathrm{~g} / 100 \mathrm{~g}$ fatty acids) and was at its lowest in May $(62.7 \pm 0.45 \mathrm{~g} / 100 \mathrm{~g}$ fatty acids, Figure 1). The spring and summer months corresponded with an increase in cis-monounsaturated fatty acids (MUFA, peaking in July, $27.2 \pm 0.24 \mathrm{~g} / 100 \mathrm{~g}$ ) and trans-MUFA (peaking in May, $6.6 \pm$ $0.26 \mathrm{~g} / 100 \mathrm{~g})$. The concentration of total $\mathrm{n}-3$ polyunsaturated fatty acids (PUFA) was highest $(0.88 \pm 0.044 \mathrm{~g} / 100 \mathrm{~g})$ in June. The effect of month was significant $(P<0.05)$ for SFA, cis-MUFA, trans-MUFA and n-3 PUFA. There was also an effect $(P<0.05)$ of supermarket on cis-MUFA, trans-MUFA, n-3 PUFA and n-6 PUFA.

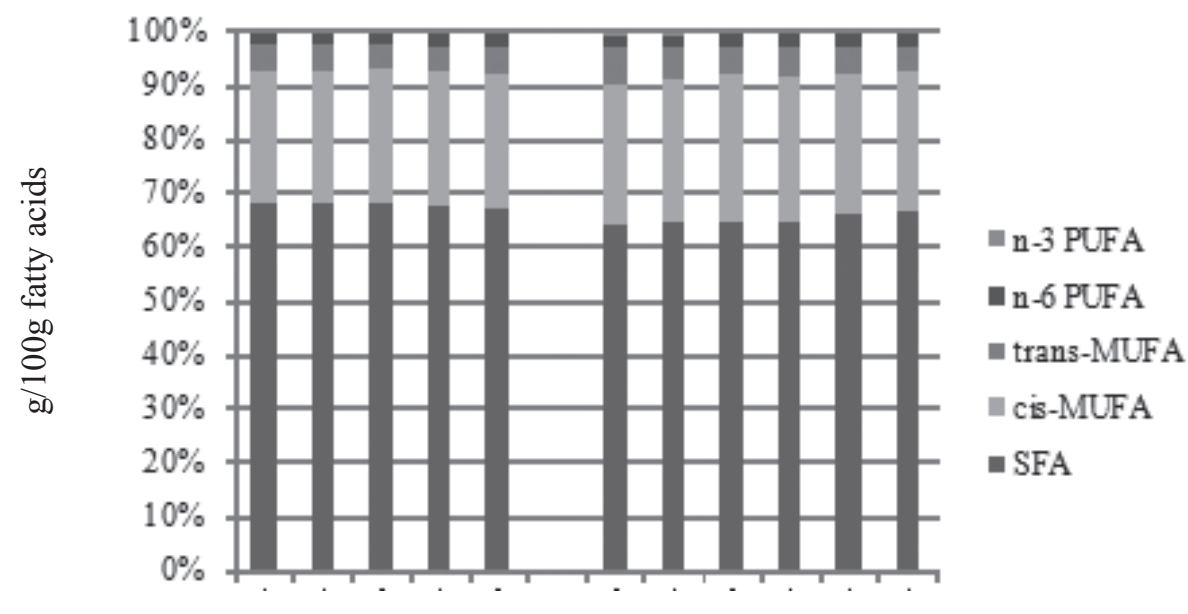

$$
\text { 之 }
$$

Where

PUFA $=$ polyunsaturated fatty acids MUFA = monounsaturated fatty acids $\mathrm{SFA}=$ saturated fatty acids

Figure 1 Fatty acid composition of semi-skimmed milk from five supermarkets over the course of one year (2008-2009)

Conclusions These results demonstrate that the seasonal effect of dairy cow diet on milk fatty acid profile is present even in bulked milk samples sourced from multiple suppliers. The reduction in SFA during the summer months is probably a response to increased dairy cow intake of fresh pasture, the higher PUFA content of which indirectly inhibits de novo synthesis and increases the availability of PUFA and trans-MUFA to the mammary gland. The observed effect of supermarket may reflect differences in supply pools. Despite the variation observed, within months all milk fat contained 63 to $68 \mathrm{~g} / 100 \mathrm{~g}$ SFA indicating considerable scope for reduction throughout the whole year.

\section{References}

Givens, D. I., and Kliem, K. E. 2008. In Functional and Speciality Beverage Technology (Woodhead publishing) $135-169$. Henderson, L., Gregory, J., Irving, K. et al., 2003. The National Diet and Nutrition Survey Volume 2. The Stationery Office, UK.

Hulshof, K. F. A. M., van Erp-Baart, M. A., Anttolainen, M. et al., 1999. European Journal of Clinical Nutrition 53, $143-$ 157.

Kliem, K. E., Morgan, R., Humphries, D. J. et al., 2008. Animal 2, 1850-1858. 